\title{
Unusual Glomus Tumor of the Penis
}

\author{
Gautam Dagur $^{\mathrm{a}} \quad$ Kelly Warren $^{\mathrm{a}} \quad$ Yimei Miao $^{\mathrm{a}} \quad$ Navjot Singh $^{\mathrm{a}}$ \\ Yiji Suha Sardar A. Khan ${ }^{a, b}$ \\ aDepartment of Physiology and Biophysics, ${ }^{b}$ Department of Urology, SUNY at Stony Brook, New York, USA
}

\section{Key Words}

Glomus tumor • Subungual region - Hamartomas • Penis • Pain

\begin{abstract}
Introduction: Glomus tumors are benign neoplasms commonly found in subungual regions of the extremities and rarely located in the penis. Misdiagnosis of glomus tumors is common; therefore, symptoms and clinical presentations should be reviewed. Objective: The primary objective of this review article is to emphasize the pathogenesis, pathology, clinical presentation, symptoms, diagnosis, and treatment methods of glomus tumors in order to better identify and manage the condition. Materials and Methods: Research was conducted using PubMed/Medline. The inclusion criteria required glomus tumor to be present on the penis. Results: Glomus tumors, which appear as symptomatic or asymptomatic lesions, are attributed to dispersion grouping of neoplastic or non-neoplastic lesions in a particular area. Conclusion: Differential diagnosis of glomus tumors includes hemangiomas, neurofibromatosis, epithelial lesions, and spindle-cell lesions. Physical examination and histological findings should be used for diagnosis. Treatment options can be either conservative or invasive, in which the patient undergoes surgical excision.

Copyright $\odot 2015$ S. Karger AG, Basel
\end{abstract}

\section{Introduction}

Glomus tumors are rare neoplasms found mostly in subungual regions of the extremities. They are frequently benign soft tissue tumors that arise from the glomus body, a component of the dermis layer involved in thermoregulation and skin circulation [1]. Certain red or blue nodules are usually benign and sometimes asymptomatic. However, there are rare malignant lesions that are usually misdiagnosed as hemangiomas or venous malformations [2, 3]. Symptoms include paroxysmal pain by temperature change or pressure. Histologic staining methods are diagnostic of glomus tumors. Surgical removal of the glomus tumor, with postoperative follow-up to avoid recurrence or malignancy, is essential.

\section{Historical Perspectives}

Glomus tumors have been described in almost every part of the body. Hippocrates recorded cases of glomus tumors during the ancient Greek era [4]. The first accurate clinical description was by William Wood who described the tumors as "painful subcutaneous tubercles" in 1812 [4]. In 1878, Kolaczek described the subungual location of the glomus tumor, but classified it as variant angiosarcoma [4]. In 1924, Paul Masson published descriptions of the first histological features of glomus tumors $[5,6]$.

\section{KARGER}

Fax +4161306 1234

E-Mail karger@karger.ch

www.karger.com
(C) 2015 S. Karger AG, Basel

1015-9770/15/0093-0113\$38.00/0

Accessible online at:

www.karger.com/cur
Sardar A. Khan

HSC Level 9 Room 040 SUNY at Stony Brook, Stony Brook NY 11794-8093, New York (USA)

E-Mailskysalik@gmail.com 


\section{Pathogenesis and Pathology}

Glomus tumors are mesenchymal neoplasms that comprise up to $2 \%$ of soft tissue tumors $[6,7]$. The majority of glomus tumors are found on fingers or toes [8]. Glomus tumor is caused by a large number of neoplastic or non-neoplastic lesions either dispersed or grouped in an anatomical area. The glomus body is a thermoregulator in the form of arteriovenous anastomosis localized in dermal and precoccygeal soft tissue [9-11]. Glomus tumors are composed of varying proportions of vessels, smooth cells, and glomus cells. The common subungual tumors are well-circumscribed proliferations of capillary-sized vessels surrounded by cuffs of glomus cells. Glomus tumor is associated with neurofibromatosis, which is a common disorder that arises secondary to mutations in the tumor suppressor gene NF1 [9].

Brems et al. [9] discussed an association between germ line, somatic mutations, and glomus tumors. Germ line mutations in NF1 were found in all subjects presenting with glomus tumors. Somatic NF1 mutations were identified in alpha-SMA-positive glomus cells and were associated with NF1 glomus tumors.

Unusual features of atypical glomus tumors include large size, deep location, infiltrative growth, mitotic activity, nuclear pleomorphism, and necrosis [12]. Atypical features are usually observed in the center with a rim of benign appearing glomus tumors. Malignant glomus tumors frequently feature a deep location, a diameter of more than $2 \mathrm{~cm}$, infiltrative growth, atypical mitotic figures, moderate to high nuclear grade, and 5 mitotic figures or more [13-16].

Glomus tumors often occur in children and adolescents, with prevalence towards males. Multiple glomus tumors are more prevalent in females. Most glomus tumors are solitary, but about $10 \%$ exist as multiple variants with hereditary familial tendency [17-20]. The gene for the multiple inherited variant has been linked to chromosome 1p21-22.3. This mutation is transmitted in an autosomal dominant fashion with incomplete penetrance and occurs $10 \%$ of the time. Expression of these inherited tumors vary by individuals [21].

Glomus tumors may be asymptomatic or symptomatic with local pain. Glomus tumors arise as small bluered nodules from the glomus body, which is found in the adventitial layer of the blood vessels. A normal glomus body is an arteriovenous shunt related to thermoregulation $[9,22]$. Glomus tumors are benign hamartomas that arise in areas rich with glomus bodies, located in the subungual regions. The mass is a neuro-myoarterial receptor that normally acts as a thermal regulator and regulates arteriolar blood flow of skin temperature [7]. The normal glomus body is comprised of both smooth muscle cells and epithelial-type cells surrounded by a fibrous capsule [22]. Glomus tumors in the penis are rarely found in the distal region of the glans penis.

Glomus tumors of the penis and soft tissue tumors are rare. There are very few cases reported in the literature. Glomus tumors occur on the glans penis, on the right corpora of the penis, and as periurethral masses [7, 9, 21, 23-26]. Penile lesions are sometimes accompanied by glomus tumors in the fingers and feet [22]. Clinical presentations of glomus tumors of the penis may be asymptomatic or have symptoms such as tenderness to palpitation, priapism, and perineal pain [21-23]. Cells from the glomus tumor of the glans penis were arranged in cords, and demonstrated no pleomorphism or increased mitotic activity [7].

Pathologists should recognize morphological variations of glomus tumors. Misdiagnosis of the glomus tumors as neurofibromatosis frequently occurs [5, 9]. Harrison et al. [27, 28] used Fisher's statistical test to identify and assess the significance of the association between these two conditions. They discovered that $29 \%$ of the patients with glomus tumors also had a history of neurofibromatosis, providing a strong epidemiologic association [27, 28]. Epithelioid glomus tumors are also of particular importance because they may be mistaken for epithelial lesions of spindle-cell lesions, such as schwannoma, liomyoma, hemangiopericytoma. Immunohistochemical and ultrastructural studies indicate that epithelioid glomus tumors have characteristics identical to those of conventional glomus tumors. The cells showed features consistent with smooth muscle derivation. The epithelioid areas frequently exhibited cytological atypical features that were believed to be manifestations of cellular degeneration rather than evidence of neoplastic progression [29].

High power field high nuclear grade alone, infiltrative growth, and vascular space involvement are not associated with metastasis. A symplastic tumor is an atypical glomus tumor that reveals high-grade nuclear pleomorphism without large size, deep location, infiltrative growth, mitotic activity, and necrosis. Despite its high-grade nuclear pleomorphism, its behavior is benign [30]. Glomangiomatosis is a rare presentation of glomus tumor described as glomus cells in an angiomatosis [31]. It reveals histologic features of diffuse angiomatosis and excess glomus cells [12]. 


\section{Genetic Aspect of Glomus Tumors}

Mosquera et al. [32] study indicated that a fusion of MIR143-NOTCH fusions were prominent in benign and malignant tumors.

\section{Location of Glomus Tumors}

Glomus bodies are naturally distributed around the body in the skin, specifically in subungual regions [24]. Glomus tumors in the subungual or subcutaneous region are usually solitary, but multiple lesions have been found on the glans penis [21]. Glomus tumor develops as small blue-red nodules usually located in the deep dermis or subcutis of upper or lower extremities [6]. Tumors arise from growth of one or more components of the normal glomus body. Tumors are not restricted to typical regions. They appear in areas without normal glomus bodies. Glomus tumors can also be found as "glomangioma"-a benign vascular tumor typically encountered at extremities, but also rarely in stomach, lung, urethra, or vagina [29]. Rare encounters of glomus tumors can also present on the glans penis $[7,21,22,25,33]$.

\section{Symptoms and Clinical Presentation of Glomus Tumors}

Subcutaneous nodules may vary from red, purple, or blue, depending on the depth of the lesions. Glomus tumors of the penis often present as localized masses with pain. Male pediatric patients present with penile lesions of dilated vascular spaces filled with blood, surrounded by rims of glomus cells [7]. The tumor may also emerge with localized tenderness and sensitivity to colder temperatures and palpitation. If these tumors are stimulated by cold, they precipitate a temperature change of the entire extremity.

Glomus tumors of the penis can be asymptomatic for many years through adolescence. Although patients with benign glomus tumors often find it painful, patients with malignant masses typically complain of discomfort. Malignant glomus tumor of the penis can develop as priapism and mild phimosis [7, 23]. In rare instances, multiple congenital glomus tumors may present as painless, plaque-like lesions [23].

Soft glomus tumors on the shaft of the penis have a $66.7 \%$ chance of being malignant. A case study patient, who presented with a malignant tumor of the penis, had an initial symptom of priapism, but it was caused by post-traumatic vascular injury leading to an arterio-lacunar fistula [23]. Another young male adult patient with painful lesions on the glans penis exhibited mild phimosis [7].

Additional cases reported by Kamarshev et al. [34] and Enzinger et al. [35] also showed benign tumors located in the subungual of the index finger in 62 and 78 year old females, which were defined as a glomus tumor exhibiting nuclear atypia similar to malignant tumors. From these findings, cellular atypia and nuclear pleomorphism are not considered a definite marker of malignancy [34].

Malignant glomus tumors found in soft tissues can metastasize to cardiac and pulmonary areas [3, 23, 36]. The former lesions in patients have led to metastases and recurrence after the excision of the tumor [13-16, 37]. A case study by Folpe et al. [37] documented 7 recurrences, 8 metastases, and 7 deaths from the disease.

\section{Clinical Diagnosis of Glomus Tumor of the Penis}

A triad of excruciating pain, localized tenderness, and cold sensitivity is the key to diagnosing the glomus tumors [2]. Hildreth's test, known as the "ischemia test", helps diagnose glomus tumors by asking patients to palpate and assess the tenderness of the site of pain [38]. This test involves decreasing and increasing blood flow via inflation and deflation of a cuff surrounding the tumor. Hildreth's test is positive if pain decreases on inflation and increases on deflation [39]. Other diagnostic steps include transillumination of digits, pinpoint localization, ice test, and spraying of alcohol to freeze the area and produce pain [3, 36-39]. Love's test locates the pain and tenderness to a specific site by using a pinhead, ballpoint pen, end of a paperclip, or Kirschner wire to press on the skin covering the tumor [37, 40, 41].

The mechanism of pain generation in patients with glomus tumor is related to exposure to cold temperature. The activation of transient receptor potential (TRP) channels is responsible for pain. TRP channels are cellular sensors that generate temperature and pain sensations, and are stimulated by physical and chemical changes in the tumor bed [42-44]. Transient receptor potential melastatin (TRPM)-8 is a temperature sensitive ion channel with a threshold of about $26-31{ }^{\circ} \mathrm{C}$ [45]. It is activated by cooling and noxious cold [46]. TRPM- 8 is found in sensory neurons that transmit nociceptive neural signals to the spinal cord and brain. TRP channels are involved 
in local dilation and constriction of blood vessels and can evoke pain, thus explaining the correlation between temperature sensitivity, vasodilation, and pain in glomus tumors [44].

\section{Histology Including Electron Microscopic Findings of the Glomus Tumor}

Diagnosis of glomus tumors of the penis is based on MRI, microscopic, and immunohistochemical findings $[21,23]$. However, treatment of glomus tumors should not be solely based on clinical findings as some tumors that histologically test positive for malignancy may behave as benign masses [26].

Histologically, glomus tumors show positive reactions of the tumor cells to smooth muscle alpha, smooth muscle actin and vimentin $[22,23]$. There are endothelium-lined vascular spaces surrounded by masses of epitheloid cells, which were divided as vascular, myxoid, and solid masses [2, 47, 48]. The tumor cells exhibit a polygonal, uniform appearance of round to ovoid nuclei, with single large nucleoli with a slightly eosinophilic cytoplasm, forming solid sheets of cells interrupted by vessels of varying size [2]. Vessels surrounding glomus tumors contain thick cellular walls and small lumen that make up the Suquet-Hoyer canal [49]. The vessels of the tumor increase in number, consisting largely of glomus cells. Nonmyelinated nerves lie along the border of the cell wall in close proximity to nearby Schwann cells and fibroblasts. Basal lamina surrounds individual cells of the cell wall and fibrils fill the cytoplasm [49]. The glomus tumors show differentiation toward smooth muscle tissue, so detection of actin isoforms is a positive confirmation of glomus tumors [50].

Under electron microscope, the tumor cells prove to be smooth-muscle cells; therefore, the glomus tumor is a tumor-like lesion of mesodermal origin rather than a true neoplasm [2, 20, 47].

Routine stains of glomeri reticulin impregnation are done in addition to hematoxylin and eosin staining for the cells presented in the male patient. The glomus cells of the penis reveal a positive cytoplasmic immunoexpression for the pan-muscle positive and negative for desmin, CD31, and CD34 [21]. Histological examination of the periurethral tumor show positive for vimentin, desmin, and calponin and negative for desmin, factor VIII-related antigen, S-100 protein, neurofilament, cytokeratin, and epithelial membrane antigen [2, 24, 29, 42, 43]. Other smooth muscle markers, including smooth muscle actin, muscle-actin, caldesmon, and smooth muscle myosin are negative [24]. Additional findings reveal smooth muscle features of tumor cells, such as pinocytotic vesicles, external laminas, dense plaques, and thin filaments with dense bodies scattered within the cytoplasm [2, 42, 43]. Few cell junctions and focal basement membrane-like structures are observed. Most benign lesions are small, often between 0.1 and $0.3 \mathrm{~cm}$ in diameter and less than $1 \mathrm{~cm}$.

Malignant tumors stain positive for smooth-muscle actin [23]. Biopsies and histological examinations reveal tumors from multiple patients that are greater than $2 \mathrm{~cm}$. in diameter in visceral locations, which reveals nuclear atypia, increased nucleo-cytoplasmic ratio, and an increase in mitotic activity [3, 23, 34, 36]. Additionally, malignant glomus tumors exhibiting glomangiomatosis feature diffuse angiomatosis and excess glomus cells [37]. On the other hand, metastatic tumors did not result from tumors that showed high nuclear grade in the absence of any other malignant features, high mitotic activity and superficial location only, large size only, or deep location only [37].

\section{Radiology of Glomus Tumors}

Radiological diagnosis of glomus tumors includes ultrasound, angiogram, MRI, cavernosography, and duplex Doppler to reveal vascularity. Histological findings are favored over radiological findings in the diagnosis of glomus tumors; however, MRI and arteriography are used to observe tumor regression after treatment administration $[51,52]$.

\section{Treatment of Glomus Tumors}

Glomus tumors are removed surgically to give patients complete relief from pain and sometimes from concomitant circumcision [23, 35]. Two surgical approaches are transungual and periungual [2]. Following general anesthesia and tourniquet control, glomus tumors are surgically removed $[3,36]$. Post-operative follow-ups are essential to exclude extragenital lesions after surgery [7, $21]$. Benign glomus tumors of the penis need radical surgery to avoid local recurrence [29]. Circumcision can be used to treat penile glomus tumors with phimosis. Surrounding tissue that appears normal is removed with the tumor to exclude malignancy [21, 25, 29, 53].

Malignant tumors are treated with a combination of embolization and chemotherapy. MRI and arteriography can be performed to monitor the regression of the pe- 
nile tumor [23]. Macaluso et al. [7] described a case in which a malignant mass was removed by performing a cavertonomy. Depending on the severity and nature of the tumor, chemotherapy, resection, or other surgical procedures may be required $[22,23]$.

Furthermore, a rare case such as non-ischemic highflow priapism was treated using an oral alpha-adrenergic and diagnosed by MRI. The patient suffered from syncope and dyspnea two weeks after embolization and later received chemotherapy after glomangiosarcoma was found. The penile tumor was excised because of persistent erectile dysfunction and perineal pain [23].

\section{Conclusion}

The occurrence of glomus tumors in the penis is rare. Glomus tumors usually occur as benign neoplasms and infrequently become malignant. Most are solitary, but $10 \%$ occur as multiple lesions. Frozen sections of glomus tumors with appropriate stains are diagnostic. The tumors are surgically excised. Biopsies and specific stains are utilized to confirm the presence of glomus tumor. The postoperative recurrence rate of glomus tumors is approximately $10 \%$. MRI and arteriography can often detect postoperative recurrence. It is pertinent that patients follow-up with their physicians regularly to avoid recurrence of cancer and metastases.

\section{References}

1 Lin F, Yang M, Pu Q, Ma L, Liu C, Mei J, Guo C, Liu L: Malignant glomus tumor in pleural cavity. J Thorac Dis 2015;7:E126-130.

2 Hiruta N, Kameda N, Tokudome T, Tsuchiya K, Nonaka H, Hatori T, Akima M, Miura M: Malignant glomus tumor: a case report and review of the literature. Am J Surg Pathol 1997;21:1096-1103.

3 Khoury T, Balos L, McGrath B, Wong MK, Cheney RT, Tan D: Malignant glomus tumor: a case report and review of literature, focusing on its clinicopathologic features and immunohistochemical profile. Am J Dermatopathol 2005;27:428-431.

4 Shugart RR, Soule EH, Johnson EW Jr: Glomus tumor. Surg Gynecol Obstet 1963;117: 334-340.

5 Strahan J, Bailie HW: Glomus tumour. A review of 15 clinical cases. Br J Surg 1972;59: 91-93.

6 De Maerteleire W, Naetens P, De Smet L: Glomus tumors. Acta Orthop Belg 2000;66: 169-173.

7 Macaluso JN Jr, Sullivan JW, Tomberlin S: Glomus tumor of glans penis. Urology 1985; 25:409-410.

8 Nazzi V, Bagatti D, Mazibrada J, Franzini A: Glomus tumor closely related to a branch of the left sural nerve: a case of a rare lesion occurring at unusual location. Acta Neurochir (Wien) 2015;157:1619-1622.
9 Brems H, Park C, Maertens O, Pemov A, Messiaen L, Upadhyaya M, Claes K, Beert E, Peeters K, Mautner V, Sloan JL, Yao L, Lee CC, Sciot R, De Smet L, Legius E, Stewart DR: Glomus tumors in neurofibromatosis type 1: genetic, functional, and clinical evidence of a novel association. Cancer Res 2009;69:7393-7401.

10 Gombos Z, Zhang PJ: Glomus tumor. Arch Pathol Lab Med 2008;132:1448-1452.

11 Gombos Z, Fogt F, Zhang PJ: Intraosseous glomus tumor of the great toe: a case report with review of the literature. J Foot Ankle Surg 2008;47:299-301.

12 Gould EW, Manivel JC, Albores-Saavedra $\mathrm{J}$, Monforte $\mathrm{H}$ : Locally infiltrative glomus tumors and glomangiosarcomas. A clinical, ultrastructural, and immunohistochemical study. Cancer 1990;65:310-318.

13 Lemmer KE: Glomus tumors; a summary of 15 cases. Arch Surg 1948;57:531-538.

14 Mathis WH Jr, Schulz MD: Roentgen diagnosis of glomus tumors. Radiology 1948;51: 71-76.

15 Smith FB: Glomus tumors in unusual locations; report of five cases and review of the literature. Portland Clin Bull 1948;2:3-11.

16 Perlow S, Roth HA: Glomus tumors. Ill Med J 1948;93:162-164.
17 Falleti J, Vita G, De Cecio R, Schonauer F, Insabato L, Natella V, Mascolo M: Symplastic glomus tumor: report of a challenging lesion with literature review. Pathol Res Pract 2012;208:372-375.

18 Mooradian AD, Viosca SP, Kaiser FE, Morley JE, Korenman SG: Penile Raynaud's phenomenon: a possible cause of erectile failure. Am J Med 1988;85:748-750.

19 Sato M, Shirasuna K, Sakuda M, Yanagawa T, Yoshida H, Imai J, Maeda N, Kubo K, Yura Y, Miyazaki T, Yagi T: Fine structure of a glomus tumor of the tongue and expression of $\mathrm{C}$ type virus in its tumor cells. Int J Oral Surg 1979:8:199-204

20 Venkatachalam MA, Greally JG: Fine structure of glomus tumor: similarity of glomus cells to smooth muscle. Cancer 1969;23: 1176-1184.

21 Szumilo J, Fronczek A, Lewkowicz D, Osemlak P: Multiple glomangiomas involving the glans penis in pediatric patient. J Low Genit Tract Dis 2011;15:250-253.

22 Saito T: Glomus tumor of the penis. Int J Urol 2000;7:115-117.

23 Masson-Lecomte A, Rocher L, Ferlicot S, Benoit G, Droupy S: High-flow priapism due to a malignant glomus tumor (glomangiosarcoma) of the corpus cavernosum. J Sex Med 2011;8:3518-3522. 
24 Malowany JI, Rieckenberg RM, Okafo BA, Colgan TJ: Glomus tumor presenting as a periurethral mass. J Low Genit Tract Dis 2008; 12:316-319.

25 Park DS, Cho TW, Kang H: Glomus tumor of the glans penis. Urology 2004;64:1031.

26 Kiyosawa T, Umebayashi Y, Nakayama Y, Soeda S: Hereditary multiple glomus tumors involving the glans penis. A case report and review of the literature. Dermatol Surg 1995; 21:895-899.

27 Harrison B, Sammer D: Glomus tumors and neurofibromatosis: a newly recognized association. Plast Reconstr Surg Glob Open 2014; 2:e214.

28 Harrison B, Moore AM, Calfee R, Sammer DM: The association between glomus tumors and neurofibromatosis. J Hand Surg Am 2013;38:1571-1574.

29 Pulitzer DR, Martin PC, Reed RJ: Epithelioid glomus tumor. Hum Pathol 1995;26:10221027.

30 Chong Y, Eom M, Min HJ, Kim S, Chung YK, Lee KG: Symplastic glomus tumor: a case report. Am J Dermatopathol 2009;31:71-73.

31 Jalali M, Netscher DT, Connelly JH: Glomangiomatosis. Ann Diagn Pathol 2002;6:326328.

32 Mosquera JM, Sboner A, Zhang L, Chen CL, Sung YS, Chen HW, Agaram NP, Briskin D, Basha BM, Singer S, Rubin MA, Tuschl T, Antonescu CR: Novel MIR143-NOTCH fusions in benign and malignant glomus tumors. Genes Chromosomes Cancer 2013;52: 1075-1087.

33 Khoudary KP, Nasrallah PF, Gordon DA: Glomus tumor of the penis. J Urol 1996;155:707.

34 Kamarashev J, French LE, Dummer R, Kerl $\mathrm{K}$ : Symplastic glomus tumor-a rare but distinct benign histological variant with analogy to other 'ancient' benign skin neoplasms. J Cutan Pathol 2009;36:1099-1102.
35 Enzinger FM, Weiss SW, Liang CY: Ossifying fibromyxoid tumor of soft parts. A clinicopathological analysis of 59 cases. Am J Surg Pathol 1989:13:817-827.

36 Joseph FR, Posner MA: Glomus tumors of the wrist. J Hand Surg Am 1983;8:918-920.

37 Folpe AL, Fanburg-Smith JC, Miettinen M, Weiss SW: Atypical and malignant glomus tumors: analysis of 52 cases, with a proposal for the reclassification of glomus tumors. Am J Surg Pathol 2001;25:1-12.

38 Hildreth DH: The ischemia test for glomus tumor: a new diagnostic test. Rev Surg 1970; 27:147-148.

39 Giele H: Hildreth's test is a reliable clinical sign for the diagnosis of glomus tumours. $\mathrm{J}$ Hand Surg Br 2002;27:157-158.

40 Jawalkar H, Maryada VR, Brahmajoshyula V, Kotha GK: Subungual glomus tumors of the hand: Treated by transungual excision. Indian J Orthop 2015;49:403-407.

41 Hazani R, Houle JM, Kasdan ML, Wilhelmi BJ: Glomus tumors of the hand. Eplasty 2008;8:e48.

42 Hirose K, Matsui T, Nagano H, Eguchi H, Marubashi S, Wada H, Morii E: Atypical glomus tumor arising in the liver: a case report. Diagn Pathol 2015;10:112.

43 Hirose T, Hasegawa T, Seki K, Yang P, Sano T, Morizumi H, Tsuyuguchi M: Atypical glomus tumor in the mediastinum: a case report with immunohistochemical and ultrastructural studies. Ultrastruct Pathol 1996;20:451456.

44 Zheng J: Molecular mechanism of TRP channels. Compr Physiol 2013;3:221-242.

45 Reid G: ThermoTRP channels and cold sensing: what are they really up to? Pflugers Arch 2005:451:250-263.
46 Stucky CL, Dubin AE, Jeske NA, Malin SA, McKemy DD, Story GM: Roles of transient receptor potential channels in pain. Brain Res Rev 2009;60:2-23.

47 Tsuneyoshi M, Enjoji M: Glomus tumor: a clinicopathologic and electron microscopic study. Cancer 1982;50:1601-1607.

48 Matsuguchi H, Tsuneyoshi M, Takeshita A, Nakamura M, Kato T, Arakawa K: Noradrenaline-secreting glomus jugulare tumor with cyclic change of blood pressure. Arch Intern Med 1975;135:1110-1113.

49 Goodman TF: Fine structure of the cells of the Suquet-Hoyer canal. J Invest Dermatol 1972;59:363-369.

50 Kropman RF: Raynaud's phenomenon of the penis. J Urol 2004;171:1630.

51 Lee DY, Hwang SC, Jeong ST, Nam DC, Park JS, Lee JH, Na JB, Kim DH: The value of diagnostic ultrasonography in the assessment of a glomus tumor of the subcutaneous layer of the forearm mimicking a hemangioma: a case report. J Med Case Rep 2015;9:191.

52 Mravic M, LaChaud G, Nguyen A, Scott MA, Dry SM, James AW: Clinical and histopathological diagnosis of glomus tumor: an institutional experience of 138 cases. Int J Surg Pathol 2015;23:181-188.

53 Leonard M, Harrington P: Painful glomus tumour of the thumb in an 11-year-old child with neurofibromatosis 1. J Hand Surg Eur Vol 2010;35:319-320. 